\title{
Weldability Analysis of 316 Stainless Steel and AA1100 Alloy Hollow Tubes using Rotational Friction Welding Process
}

\author{
Y. Lekhana ${ }^{1}$, A. Nikhila ${ }^{2}$, K. Bharath ${ }^{3}$, B. Naveen ${ }^{4}$, A. Chennakesava Reddy ${ }^{5}$ \\ ${ }^{1,2,3,4}$ UG students, Department of Mechanical Engineering, JNTUH College of Engineering, Kukatpally, Hyderabad - 500 085, Telangana, \\ India
}

${ }^{5}$ Professor, Department of Mechanical Engineering, JNTUH College of Engineering, Kukatpally, Hyderabad - 500 085, Telangana, India

\begin{abstract}
The purpose of the current project work was to weld dissimilar metals of AA1100 alloy and 316 stainless steel hollow tubes by rotational friction welding. The finite element analysis has been carried out to model the rotational friction welding. The process parameters have been optimized using Taguchi techniques. The optimal process parameters for AA1100 alloy and 316 stainless steel were found to be frictional pressure of $80 \mathrm{MPa}$, frictional time of $5 \mathrm{sec}$, rotational speed of $2000 \mathrm{rpm}$ and forging pressure of $160 \mathrm{MPa}$.
\end{abstract}

Keywords: AA1100 alloy, 316 stainless steel, finite element analysis, Taguchi, rotational friction welding

\section{Introduction}

Up to date, the exploit of joints between dissimilar materials has significantly increased [1-3]. The complexities in the welding of aluminum alloy with stainless steel by fusion welding processes have been a great confront for engineering, because they result from hard and brittle intermetallic phases those are produced between aluminum and steel at elevated temperatures [4]. As a rule, all metallic engineering materials which are forgeable can be friction welded, including automotive valve alloys, maraging steel, tool steel, alloy steels and titanium alloys [5, 6]. With friction welding, joints are possible between not only two solid materials or two hollow parts, but also solid material/hollow part combinations can be reliably welded as shown in figure 1 . Therefore, friction welding has been attracting increasing attention in many applications, such as aerospace, automobiles, railway and nuclear industry.
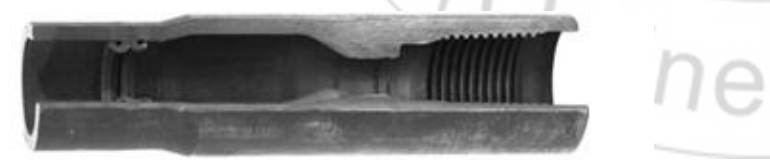

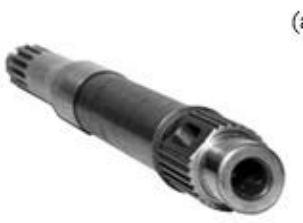

(b) (a)

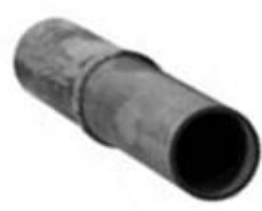

(c)
Figure 1: Some applications of friction welding process for hollow pipes/shafts: (a) Cross cut section of well drilling rod. Threaded end is friction welded to drill pipe body, (b) Marine prop shafts are an excellent bi-metal application. The wet-end is made from 17-4 stainless steel. The drive-end is sealed in the power transmission unit and is made from hardened 8620 carbon steel and (c) Join heavy wall tube to solid end to avoid extensive drilling.

In the friction welding process, the developed heat at the interface raises the temperature of workpieces rapidly to val- ues approaching the melting range of the material. Welding occurs under the influence of pressure that is applied when heated zone is in the plastic range, as mentioned in $[7,8]$. The foremost difference between the welding of similar materials and that of dissimilar materials is that the axial movement is unequal in the latter case whilst the similar materials experience equal movement along the common axis. This problem arises not only from the different coefficients of thermal expansion, but also from the distinct hardness values of the dissimilar materials to be joined. Joint and edge preparation is very important to produce distortion free welds $[9,10]$. The solid-state diffusion is slow in the wider joints [11].The intermetallic compounds can change the micro hardness near the joint interface of dissimilar metals [12].Nowadays, the finite element methods are more popular to analyze welding processes $[13,14]$.

The current work was to study the weldability of AA1100 alloy and 316 stainless steel using rotational frictional welding process. Finite element method was employed to analyze the influence of friction welding parameters on welding characteristics. Taguchi techniques were adopted for the design of experiments.

\section{Finite Element Modeling}

In the current project work, ANSYS workbench (15.0) software was used in the coupled thermal and structural analyses during friction welding of AA1100 alloy and 316 stainless steel. An axisymmetric 3D model [15] AA1100 alloy and 316 stainless steel hollow tubes of $25.4 \mathrm{~mm}$ diameter and $100 \mathrm{~mm}$ length was made using ANSYS workbench as shown in figure 2. Tetrahedron elements [16] were used to mesh the AA1100 alloy and 316 stainless steel hollow tubes. The rotating part was modeled with 4743 elements and the non-rotating part was meshed with 3825 elements. 


\section{International Journal of Science and Research (IJSR) \\ ISSN (Online): 2319-7064}

Index Copernicus Value (2013): 6.14 | Impact Factor (2015): 6.391

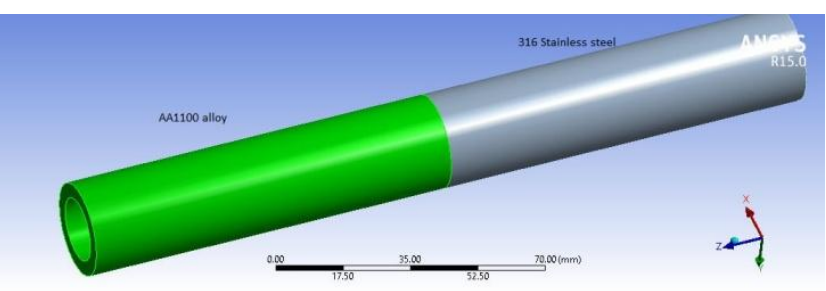

Figure 2: Geometric modeling of friction welding.

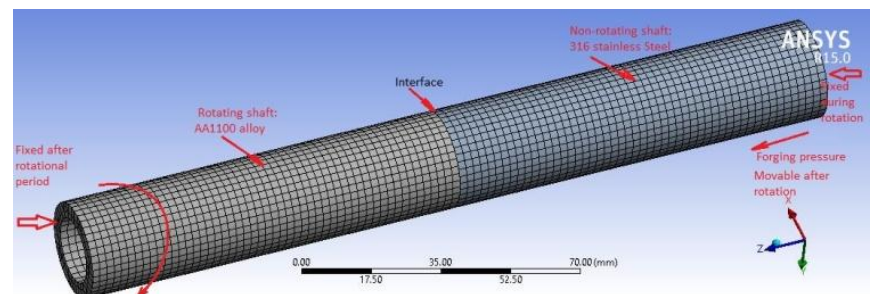

Figure 3: The boundary conditions

The boundary conditions are stated in figure 3. First the transient thermal analysis was carried out keeping 316 stainless steel tube stationary and AA1100 alloy tube in rotation. The coefficient of friction 0.2 was applied at the interface of AA1100 alloy and 316 stainless steel hollow tubes. The convection heat transfer coefficient was applied on the surface of two tubes. The heat flux calculations were imported from ANSYS APDL commands and applied at the interface. The temperature distribution was evaluated. The thermal analysis was coupled to static structural analysis. For the structural analysis the rotating (AA1100 alloy) tube was brought to stationary and the forging pressure was applied on the 316 stainless steel tube along the axis of tube. The 316 stainless steel tube was allowed to move in the axial direction. The structural analysis was conceded for the equivalent stress, bulk deformation, sliding and penetration at the interface of tubes.
Table 1: Process parameters and levels

\begin{tabular}{|c|c|c|c|c|}
\hline Factor & Symbol & Level-1 & Level-2 & Level-3 \\
\hline Frictional Pressure, MPa & A & 60 & 70 & 80 \\
\hline Frictional time, Sec & B & 4 & 5 & 6 \\
\hline Rotational speed & C & 1600 & 1800 & 2000 \\
\hline Forging pressure, MPa & D & $1.50 \mathrm{~A}$ & $1.75 \mathrm{~A}$ & $2.00 \mathrm{~A}$ \\
\hline
\end{tabular}

The analysis of friction welding was carried out as per the design of experiments using Taguchi techniques. The process parameters and their levels are given table-1. The orthogonal array (OA), L9 was selected for the current project work. The parameters were assigned to the various columns of O.A. The assignment of parameters along with the OA matrix is given in table 2 .

Table 2:Orthogonal Array (L9) and control parameters

\begin{tabular}{|l|l|l|l|l|}
\hline Treat No. & A & B & C & D \\
\hline 1 & 1 & 1 & 1 & 1 \\
\hline 2 & 1 & 2 & 2 & 2 \\
\hline 3 & 1 & 3 & 3 & 3 \\
\hline 4 & 2 & 1 & 2 & 3 \\
\hline 5 & 2 & 2 & 3 & 1 \\
\hline 6 & 2 & 3 & 1 & 2 \\
\hline 7 & 3 & 1 & 3 & 2 \\
\hline 8 & 3 & 2 & 1 & 3 \\
\hline 9 & 3 & 3 & 2 & 1 \\
\hline
\end{tabular}

\section{Results and Discussion}

The results obtained from the transient thermal analysis, structural analysis and contact analysis are discussed in the following sections. The Fisher's test was confirmed to accept all the parameters (A, B, C and D) at $90 \%$ confidence level.

\subsection{Influence of parameters on temperature distribution}

Table -3 gives the ANOVA (analysis of variation) summary of raw data. The percent contribution specifies that A (friction pressure) contributes $51.03 \%$ of total variation, B (friction time) tenders $19.17 \%$ of total variation, and $\mathrm{C}$ (rotational speed) presents $29.12 \%$ of total variation on the temperature distribution. The effect of forging pressure is negligible.

Table 3:ANOVA summary of the temperature distribution

\begin{tabular}{|c|c|c|c|c|c|c|c|c|}
\hline Source & Sum 1 & Sum 2 & Sum 3 & SS & $v$ & $V$ & $F$ & $P$ \\
\hline A & 3615.8 & 4163.6 & 4735.7 & 209062 & 1 & 209062 & 27874949 & 51.03 \\
\hline B & 3809.7 & 4212.9 & 4492.5 & 78551 & 1 & 78551 & 10473514 & 19.17 \\
\hline C & 3741.2 & 4187 & 4586.9 & 119318 & 1 & 119318 & 15909126 & 29.12 \\
\hline D & 4245.5 & 5723692.8 & 12515.1 & 2777 & 1 & 2777 & 370294 & 0.68 \\
\hline e & & & & 0.03 & 4 & 0.0075 & 1.00 & 0 \\
\hline T & 15412.2 & 5736256.3 & 26330.2 & 409709 & 8 & & & 100 \\
\hline
\end{tabular}

Note: $S S$ is the sum of square, $v$ is the degrees of freedom, $V$ is the variance, $F$ is the Fisher's ratio, $P$ is the percentage of contribution and $T$ is the sum squares due to total variation. 


\section{International Journal of Science and Research (IJSR) \\ ISSN (Online): 2319-7064}

Index Copernicus Value (2013): 6.14 | Impact Factor (2015): 6.391
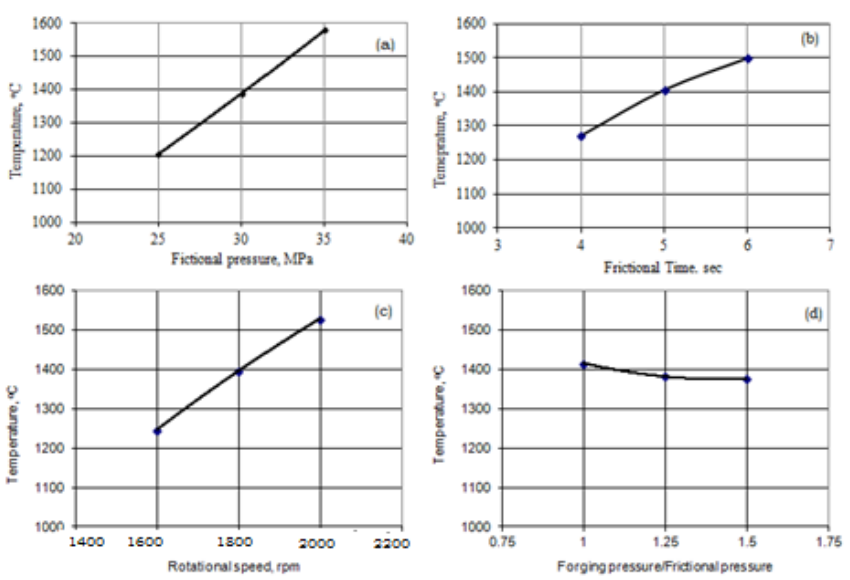

Figure4:Influence of process parameters on temperature.

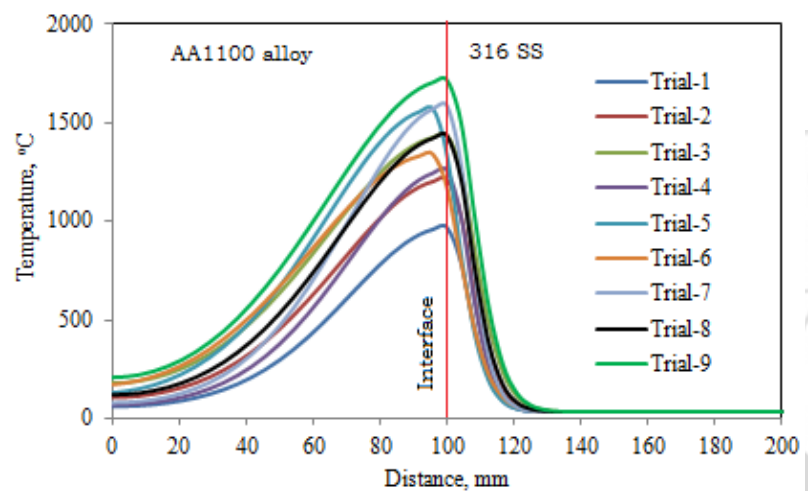

Figure 5: Temperature distribution during different trials.
The temperature developed in the welding tubes is directly proportional to the frictional pressure, frictional time and rotational speed as shown in figure $4 \mathrm{a}, 4 \mathrm{~b} \& 4 \mathrm{c}$. From figure 6 it is noticed that the temperature is very high at the interface. The highest temperature was generated for the test conditions of trial- 9 and the conditions of trial-1 gave the lowest temperature in the tubes (figure 5). In the AA1100 alloy tubethe high temperature zone widens from the weld interface due to the heat conduction within the specimen. The temperature gradient is very narrow in the 316 stainless steel tube due to low thermal conductivity.

\subsection{Influence of parameters on equivalent stress}

The ANOVA summary of the equivalent stress is given in Table 4 . The percent contribution column establishesthe major contributions $11.37 \%$ and $85.24 \%$ of friction pressure and frictional timerespectively towards variation in the effective stress. The influence of rotational speed and forging pressure are negligible.

Table 4: ANOVA summary of the equivalent stress

\begin{tabular}{|c|c|c|c|c|c|c|c|c|}
\hline Source & Sum 1 & Sum 2 & Sum 3 & SS & $v$ & $V$ & $F$ & $P$ \\
\hline A & 1729.16 & 1962.29 & 2227 & 41491 & 1 & 41491.77 & 11138730 & 11.37 \\
\hline B & 1419.48 & 1763.31 & 2736 & 311054 & 1 & 311054.8 & 83504645 & 85.24 \\
\hline C & 1855.31 & 1966.73 & 2097 & 9769 & 1 & 9769.48 & 2622679 & 2.68 \\
\hline D & 1977.2 & 1214353.1 & 5919 & 2598 & 1 & 2598.13 & 697484 & 0.71 \\
\hline E & & & & -0.0149 & 4 & -0.003725 & 1.00 & 0 \\
\hline T & 6981.15 & 1220045.4 & 12980 & 364914.17 & 8 & & & 100 \\
\hline
\end{tabular}
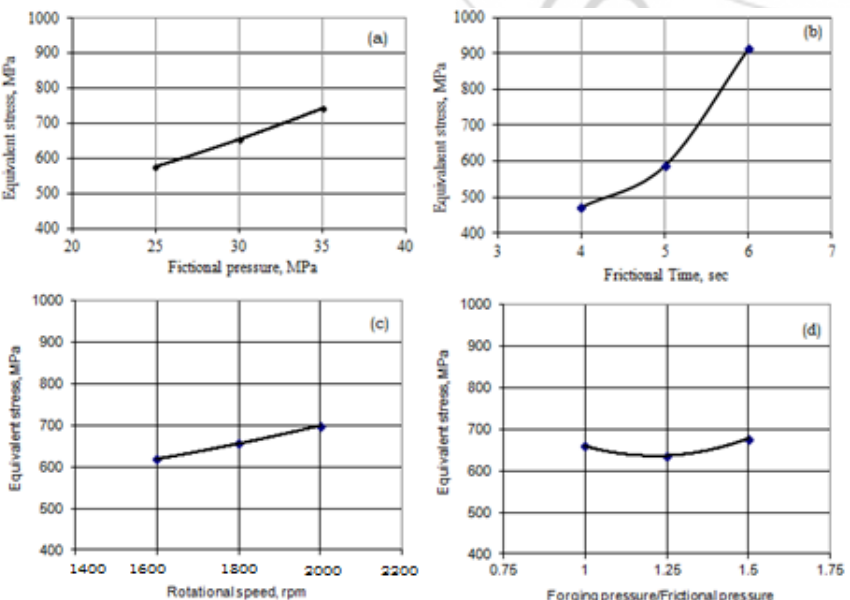

Figure 6: Influence of process parameters on equivalent stress.

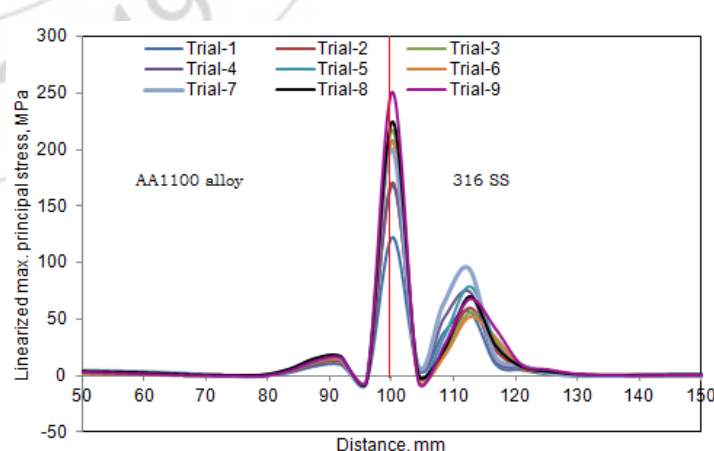

Figure 7: Linearized major principal stress of all joints.

It is observed from figure 6 that the equivalent stress increases with increase of frictional pressure, friction time and rotational speed. Both tensile and compressive stresses were generated at the contact surface (at $\mathrm{z}=0$ ) in the region of heat affected zone (HAZ). The magnitudes of tensile and compressive stresses would decrease with depth below the contact surface. However, the compressive stresses were very low as compared to the tensile stress. Also, it is observed that, the tensile stresses were high in the HAZ region 


\section{International Journal of Science and Research (IJSR) \\ ISSN (Online): 2319-7064 \\ Index Copernicus Value (2013): 6.14 | Impact Factor (2015): 6.391}

of 316 stainless steel due to recrystallization. On either side of weld joint interface, Al-rich and Fe rich regions were revealed as shown in figure 8 . It is also observed from figure 9 that the equivalent stresses are $353.98 \mathrm{MPa}$ and $996.3 \mathrm{MPa}$ for trail-1 and trial-9, respectively.
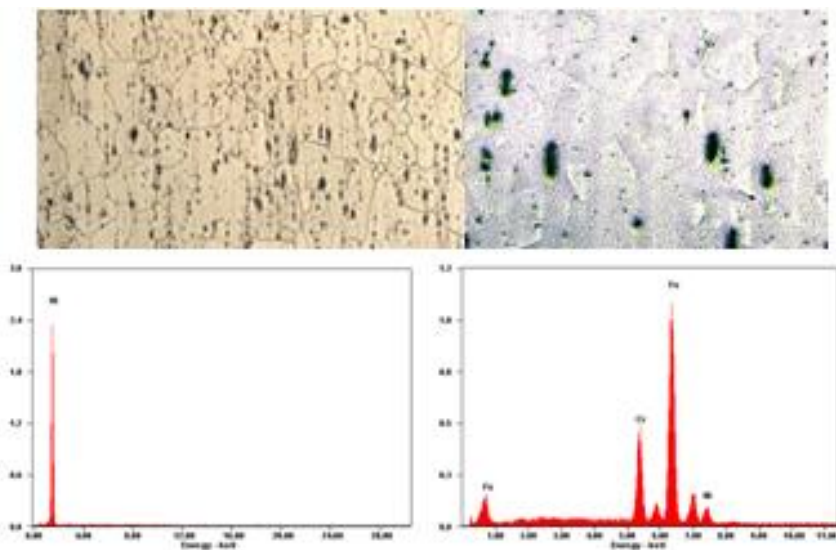

Figure 8: Microstructure and EDX analyses at the interface of friction welded joint.

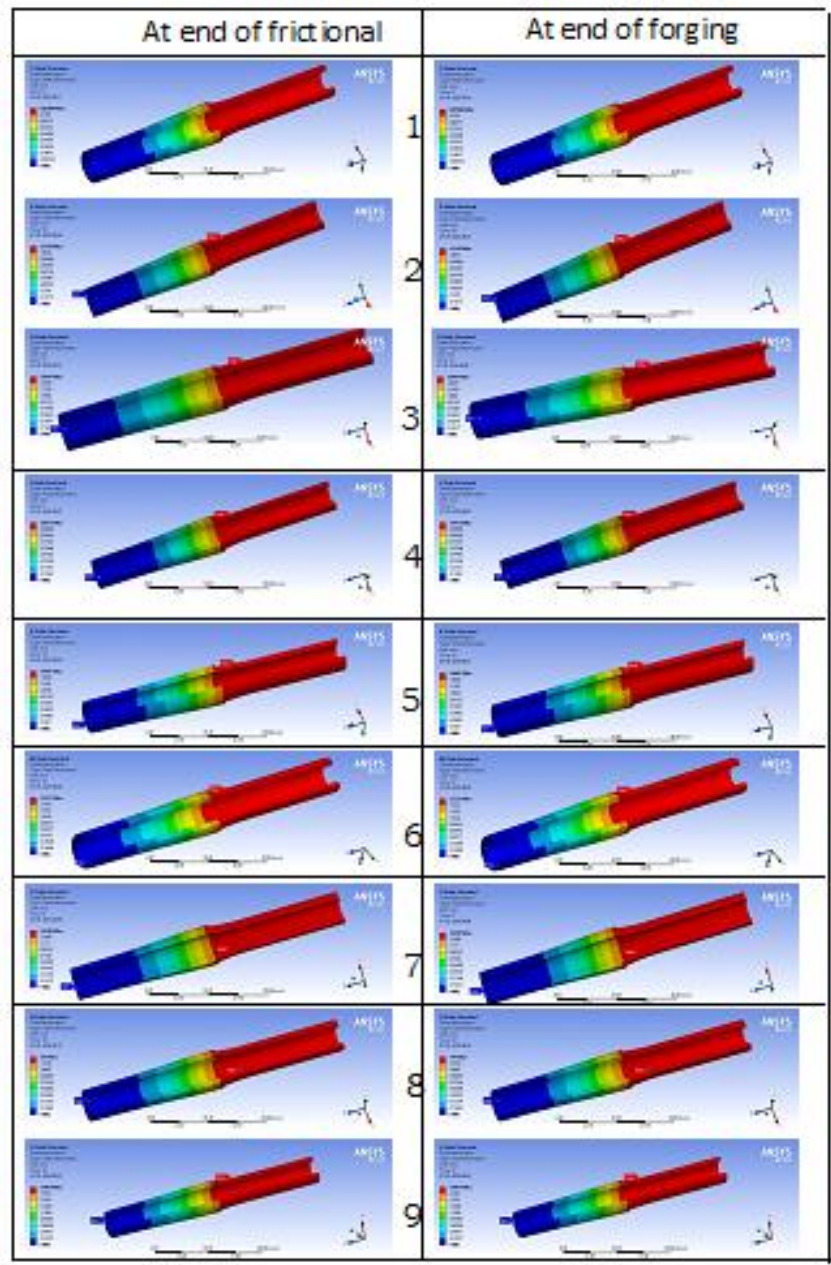

Figure 9: Equivalent stress values under different trials.

\subsection{Influence of parameters on bulk deformation}

The ANOVA summary of the bulk deformation is given in Table 6 . The frictional pressure, friction time and rotation speed contribute, respectively, $22.00 \%, 59.39 \%$ and $15.41 \%$ towards variation in the bulk deformation of frictional welded tubes. The influence of forging pressure is negligible.
Table 5: ANOVA summary of the directional deformation

\begin{tabular}{|c|c|c|c|c|c|c|c|c|}
\hline Source & Sum 1 & Sum 2 & Sum 3 & $S S$ & $v$ & $V$ & $F$ & $P$ \\
\hline A & 3.7184 & 4.2323 & 4.8196 & 0.2 & 1 & 0.2 & 1587.96 & 22 \\
\hline B & 3.352 & 4.272 & 5.1463 & 0.54 & 1 & 0.54 & 4287.50 & 59.39 \\
\hline C & 3.7897 & 4.262 & 4.7186 & 0.14 & 1 & 0.14 & 1111.57 & 15.41 \\
\hline D & 4.4854 & 5.78 & 12.7703 & 0.03 & 1 & 0.03 & 238.19 & 3.31 \\
\hline E & & & & -0.0005 & 4 & -0.000126 & 1.00 & 0 \\
\hline T & 15.3455 & 18.5463 & 27.4548 & 0.909 & 8 & & & 100 \\
\hline
\end{tabular}
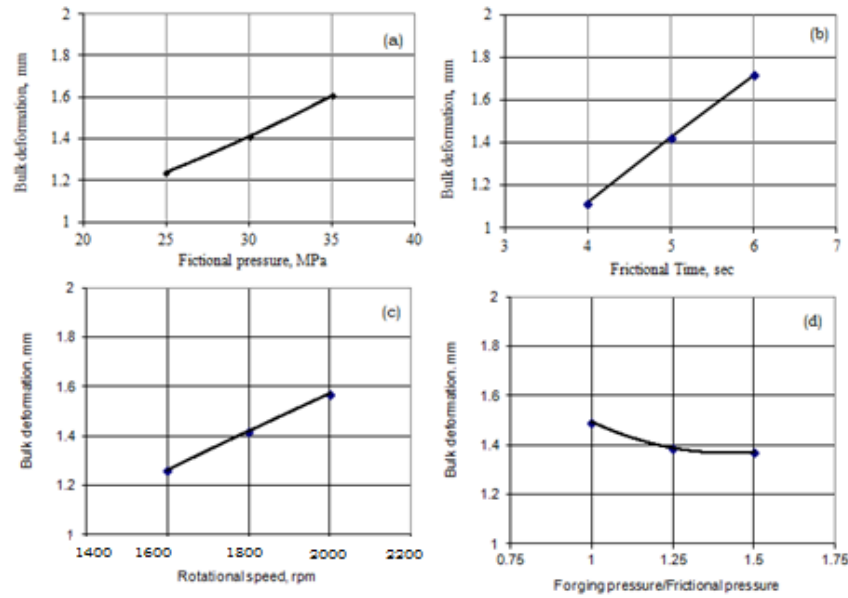

Figure 10: Influence of process parameters on bulk deformation

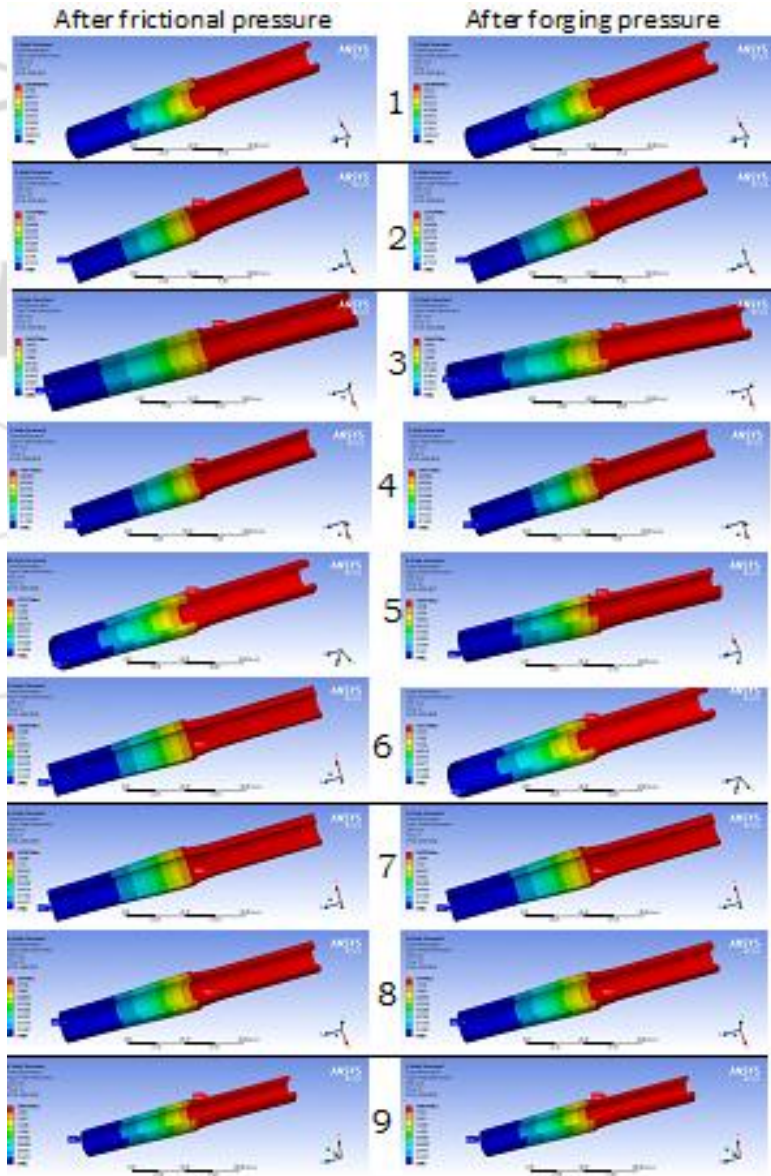

Figure 11:Bulk deformation values under different trials.

The bulk deformation increases with an increase in the frictional pressure, frictional time and rotational speed as shown in figure 10. In the first numerical iteration (thermal) the frictional load generates uniform pressure on the contact surface and conse- 


\section{International Journal of Science and Research (IJSR) \\ ISSN (Online): 2319-7064 \\ Index Copernicus Value (2013): 6.14 | Impact Factor (2015): 6.391}

quently linearly changing heat flux resulting the expansion of tubes. In the next iteration (static) the forging pressure on the contact surface forces the material to penetrate and slide resulting the contraction of tubes. As seen from FEA results illustrated in figure 11 that the trial-1 has experienced the lowest net expansion of $0.86 \mathrm{~mm}$; the trial-9 has undergone the highest net expansion of $1.98 \mathrm{~mm}$. The deformation of 316 stainless steel is very small due to its higher hardness value and higher melting point.

\subsection{Influence of parameters on penetration and sliding}

The ANOVA summary of the penetration is given in Table 6. For the penetration of materials during friction welding, the major contributions are of frictional pressure, forging pressure and rotational speed. A three-fourth contribution (73.52\%) is of frictional pressure. The second highest contribution(12.82\%) is of forging pressure. As the frictional pressure and rotational speed increase, the penetration of metal increases at the joint interface (figure 12). the penetration was high for the forging pressure to frictional pressure ratio of 2.0 .

Table 6: ANOVA summary of penetration at the interface

\begin{tabular}{|c|c|c|c|c|c|c|c|c|}
\hline Source & Sum 1 & Sum 2 & Sum 3 & $S S$ & $V$ & $V$ & $F$ & $P$ \\
\hline A & 0.0121 & 0.0139 & 0.0152 & $1.615 \mathrm{E}-06$ & 1 & $1.615 \mathrm{E}-06$ & 3230 & 73.52 \\
\hline B & 0.0137 & 0.0141 & 0.0134 & $8.2 \mathrm{E}-08$ & 1 & $8.2 \mathrm{E}-08$ & 164 & 3.71 \\
\hline C & 0.0131 & 0.0139 & 0.0142 & $2.15 \mathrm{E}-07$ & 1 & $2.15 \mathrm{E}-07$ & 430 & 9.77 \\
\hline D & 0.0137 & $5.72 \mathrm{E}-05$ & 0.0412 & $2.82 \mathrm{E}-07$ & 1 & $2.82 \mathrm{E}-07$ & 564 & 12.82 \\
\hline E & & & & $2 \mathrm{E}-09$ & 4 & $5 \mathrm{E}-10$ & 1.00 & 0 \\
\hline T & 0.0526 & 0.04196 & 0.084 & $2.196 \mathrm{E}-06$ & 8 & & & 100 \\
\hline
\end{tabular}
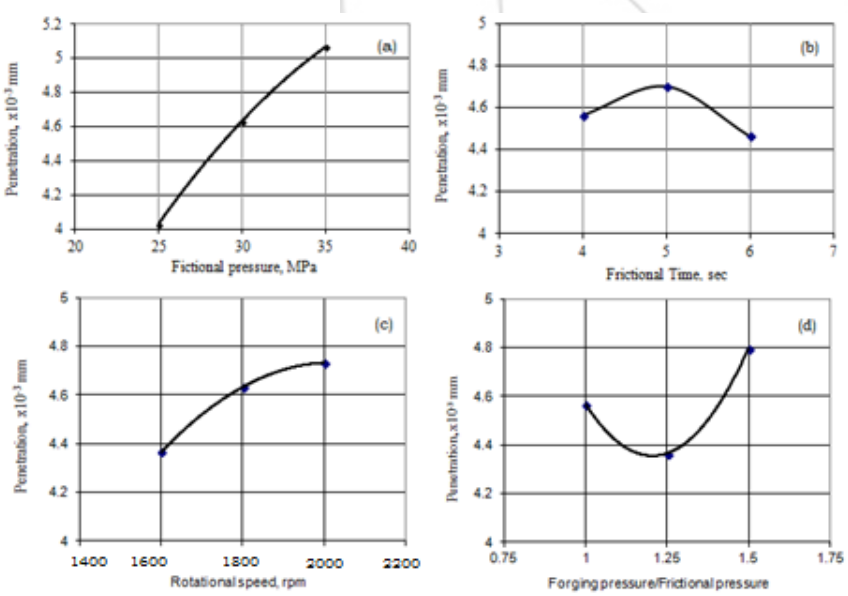

Figure 12: Influence of process parameters on penetration

The ANOVA summary of sliding at the interface is given in Table 7. The sliding of material is responsible for the formation of flash at the joint interface. The sliding of materials can be attributed to the contributions of frictional pressure, frictional time and rotational speed. The contributions of frictional pressure, frictional time and rotational speed are respectively, $50.46 \%, 37.08 \%$ and $9.68 \%$. The sliding increases with increase of all process parameters as shown in figure 13. In friction welding of AA1 100 alloy and 316 stainless steel, only AA1100 alloy is consumed in the form of flash due to softer and high thermal conductive material as most of the heat generated at the interface is transferred to AA1100 alloy.

Table 7: ANOVA summary of sliding at the interface

\begin{tabular}{|c|c|c|c|c|c|c|c|c|}
\hline Source & Sum 1 & Sum 2 & Sum 3 & $S S$ & $v$ & $V$ & $F$ & $P$ \\
\hline A & 0.404 & 0.4699 & 0.5227 & 0.00236 & 1 & 0.00236 & 4715630 & 50.46 \\
\hline B & 0.411 & 0.4736 & 0.512 & 0.0017 & 1 & 0.0017 & 3465404 & 37.08 \\
\hline C & 0.4427 & 0.46 & 0.4939 & 0.00045 & 1 & 0.00045 & 904430 & 9.68 \\
\hline D & 0.4509 & 0.0727 & 1.3966 & 0.00013 & 1 & 0.00013 & 259764 & 2.78 \\
\hline E & & & & 2E-09 & 4 & $5 \mathrm{E}-10$ & 1.00 & 0 \\
\hline T & 1.7086 & 1.4762 & 2.9252 & 0.00467 & 8 & & & 100 \\
\hline
\end{tabular}
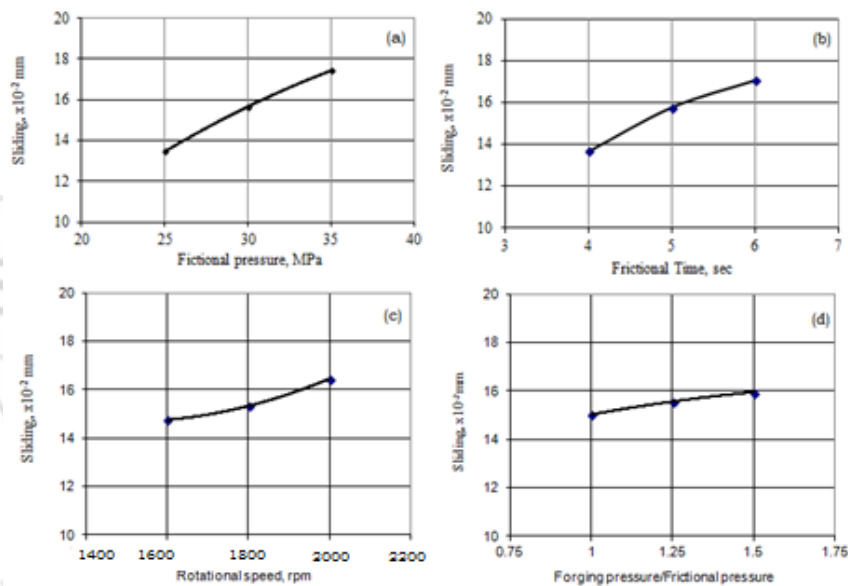

Figure 13: Influence of process parameters on sliding.

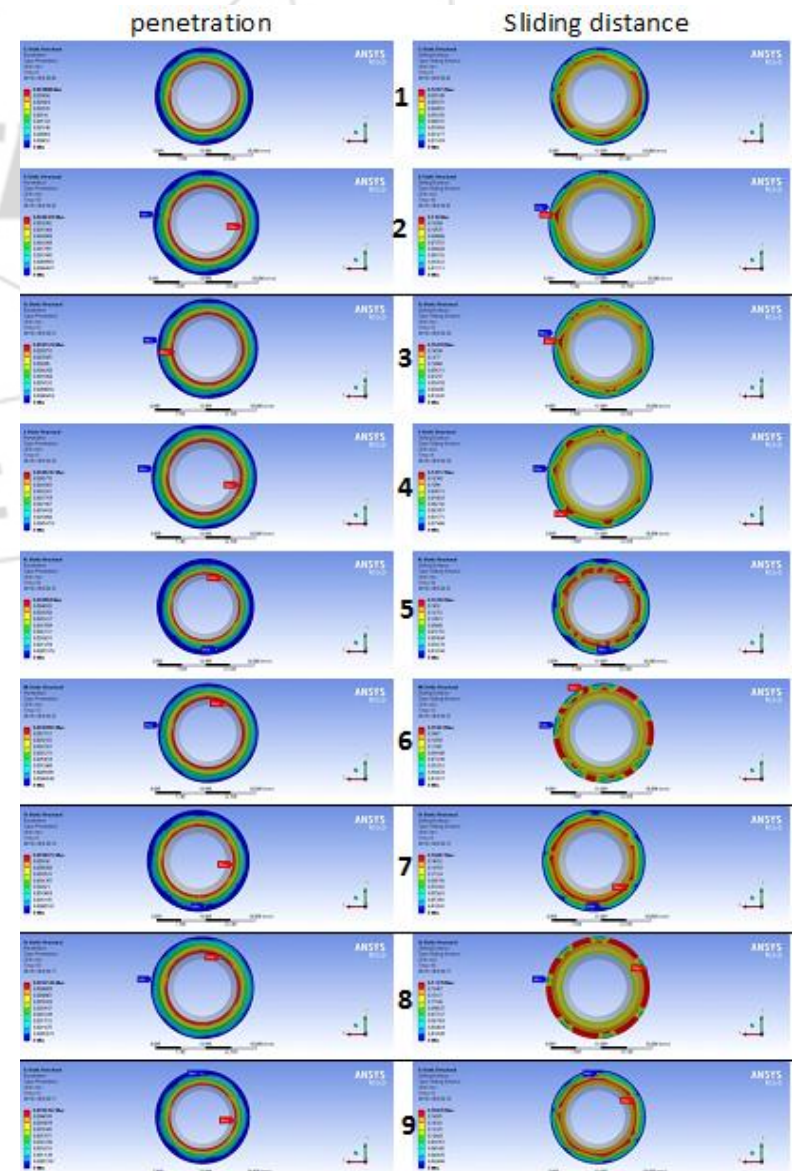

Figure 14: Sliding and penetration values under different trials. 


\section{International Journal of Science and Research (IJSR) \\ ISSN (Online): 2319-7064}

Index Copernicus Value (2013): 6.14 | Impact Factor (2015): 6.391

In the case of trail 1 the interface layer has not produced a good metallic bond between 316 stainless steel and AA1100 alloy. In the case of trail 4 and 8 the interface layer has produced a good metallic bond between aluminum and steel. A closer look at the penetration and sliding images shows that the failure of good bonding has taken place largely by interface separation (figure 14). One factor may be the uneven rate of heat generation. Due to this uneven rate of heat input, the amount of melt-off for each cycle for this welding combination of steel and aluminum varies. The other one is high hardness value of 316 stainless steel. During friction heating stage any surface irregularities are removed, the temperature increases in the vicinity of the welded surfaces, and an interface of visco-plastic aluminum is formed. During forging pressure stage there is significant thermo-plastic deformation of aluminum in the contact area. In result of this is formation of a flange-like flash. The process of welding takes place due to the plastic and diffusion effects.

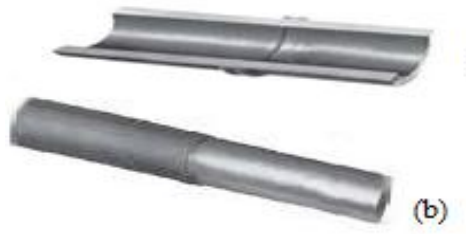

(a)

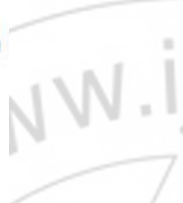

Figure 15: Cut-section of friction welded AA1100 alloy and 316 stainless steel (a) weld joint with flash removed (b).

The optimal process parameters for AA1100 alloy and 316 stainless steel are found to be frictional pressure of $80 \mathrm{MPa}$, frictional time of $5 \mathrm{sec}$, rotational speed of $2000 \mathrm{rpm}$ and forging pressure of $160 \mathrm{MPa}$. For these dissimilar metals of aluminium and steel, the forging pressure should be higher than the frictional pressure. The experimental fricitional welding validateds the the eightth trial conditions as shown in figure 15 .

\section{Conclusions}

This study shows that the 316 stainless steel and AA1100 alloy is good if the operating conditions: frictional pressure of $80 \mathrm{MPa}$, frictional time of $5 \mathrm{sec}$, rotational speed of 2000 $\mathrm{rpm}$ and forging pressure of $160 \mathrm{MPa}$. For friction welding of AA1100 alloy and 316 stainless steel the forging pressure should be higher than the frictional pressure. For this condition of welding there was good penetration and sliding of materials at the welding interface resulting a good mechanical bonding.

\section{Acknowledgements}

The author acknowledges with thanks University Grants Commission (UGC) - New Delhi for sectioning R\&D project.

\section{References}

[1] V. Srija and A. Chennakesava Reddy, "Finite Element Analysis of Friction Welding Process for 2024Al Alloy and UNS C23000 Brass," International Journal of Science and Research, 4 (5), pp. 1685-1690, 2015.

[2] T. Santhosh Kumar and A. Chennakesava Reddy, "Finite Element Analysis of Friction Welding Process for
2024Al Alloy and AISI 1021 Steel," International Journal of Science and Research, 4 (5), pp.1679-1684, 2015.

[3] A. Raviteja and A. Chennakesava Reddy, "Finite Element Analysis of Friction Welding Process for UNS C23000 Brass and AISI 1021 Steel," International Journal of Science and Research, 4 (5), pp. 1691-1696, 2015.

[4] J. Banker, A. Nobili, "Aluminum-Steel Electric Transition Joints, Effects of Temperature and Time upon Mechanical Properties, 131st Annual Meeting, Seatle, WA, USA, 2002.

[5] A. Chennakesava Reddy, "Evaluation of Parametric Significance in Friction Welding Process for AA7020 and Zr705 Alloy using Finite Element Analysis," International Journal of Emerging Technology and Advanced Engineering, 6 (2), pp. 40-46, 2016.

[6] A. Chennakesava Reddy, "Weldability of Friction Welding Process for AA2024 Alloy and SS304 Stainless Steel using Finite Element Analysis," International Journal of Engineering Research and Application, 6 (3), pp. 53-57, 2016.

[7] A. Chennakesava Reddy, "Fatigue Life Evaluation of Joint Designs for Friction Welding of Mild Steel and Austenite Stainless Steel," International Journal of Science and Research, 4 (2), pp. 1714-1719, 2015.

[8] A. Chennakesava Reddy, "Fatigue Life Prediction of Different Joint Designs for Friction Welding of 1050 Mild Steel and 1050 Aluminum," International Journal of Scientific \& Engineering Research, 6 (4), pp. 408412, 2015.

[9] A. Chennakesava Reddy, "Finite Element Analysis of Friction Welding Process for AA7020-T6 and Ti-6Al4V Alloy: Experimental Validation," International Journal of Science and Research, 4 (8), pp. 947-952, 2015.

[10] A. Chennakesava Reddy, "Evaluation of parametric significance in friction welding process for AA2024 and Zr705 alloy using finite element analysis," International Journal of Engineering Research \& Technology, 5 (1), pp. 84-89, 2016.

[11] A. Chennakesava Reddy, K. Ravaivarma, and E. Thirupathi Reddy, "A study on the effects of joint and edge preparation to produce cost reduction and distortion free welds," National Welding Seminar, IIT-Madras, 07-09th January, 2002, pp.51-55.

[12] S. Fukumoto, H. Tsubakino, K. Okita, M. Aritoshi, T. Tomita, "Amorphization by friction welding between 5052 aluminum alloy and 304 stainless steel," Scripta Materialia 42, pp. 807-812, 2000.

[13] A. Sluzalec, "Thermal effects in friction welding," International Journal of Mechanical Sciences, 32, pp. 467478, 1990.

[14] A. Chennakesava Reddy, "Analysis of welding distortion in seam and skip arc weldings using finite element method," International Journal of Mechanical Engineering Research \& Development, ISSN: 2248-9355, Vol.01, No.01, pp.12-18, 2011.

[15] Chennakesava, R. Alavala, "CAD/CAM: Concepts and Applications,” PHI Learning Pvt. Ltd, 2008:

[16] Chennakesava R. Alavala, "Finite element methods: Basic Concepts and Applications, PHI Learning Pvt. Ltd., 2008. 